\title{
Drivers of Change in Food Choice Behavior of Rural Households in Adola Rede District, East Guji Zone, Ethiopia
}

\author{
Korji Dembi $^{1}$ (MSc), Seyoum Chanyalew ${ }^{2}$ (PhD) and Gezahegn Muluken ${ }^{2}$ (PhD) \\ ${ }^{1}$ Socio-economic and Agricultural Research Extension Division, Bore Agricultural Research Center, Oromia \\ Agricultural Research Institute, P.O.Box 904, Finfine, Ethiopia \\ ${ }^{2}$ Department of Rural Development and Agricultural Extension, College of Agriculture and Environmental Science, \\ Haramaya University, Dire Dawa, Ethiopia
}

How to cite this paper: Korji Dembi, Seyoum Chanyalew and Gezahegn Muluken. (2019) Drivers of Change in Food Choice Behavior of Rural Households in Adola Rede District, East Guji Zone, Ethiopia. International Journal of Food Science and Agriculture, 3(3), 241-252.

DOI: 10.26855/ijfsa.2019.09.014

*Corresponding author: Korji Dembi, Socioeconomic and Agricultural Research Extension Division, Bore Agricultural Research Center, Oromia Agricultural Research Institute, P.O.Box 904, Finfine, Ethiopia. Tell: +251920470209 .

Email: korjidembi@gmail.com

\begin{abstract}
Global commitment to improving nutrition among the most vulnerable has never been higher or more coordinated. Scaling up of evidence based, nutrition specific intervention with the most potential for improving nutritional outcomes and attention to nutrition -sensitive development for long term sustainability of improvements in nutrition have framed the global response. Attempts to achieve ambitious goals have led to identification of key challenges, including recognition of the limited knowledge about drivers of food choice (DFC), particularly among the poor in low and middle income countries (LMIC). Malnutrition is attributed to lack of adequate and balanced diet and is considered as a major cause of decreased productivity and thus exacerbate poverty and can lead to health problem for majority of the population of Ethiopia. This study assessed food choice behavior and consumption among rural households and perception of rural households in the Adola Rede district, Ethiopia. Probability proportional to size was used to determine numbers of study sites and sample households while random sampling techniques was used to draw study sites and sample respondents from each study sites. Data was collected from 150 sample respondents using interview and focus group discussions. Descriptive statistics were employed in analyzing socio economic characteristics of the respondents. Food choice behavior of the rural households was categorized depending on Food Consumption Score used widely by World Food Program. The food choice behaviors of the households respondents were $30 \%$ poor, $45 \%$ borderline and $25 \%$ adequate food choice behavior. Overwhelmingly, only one- fourth of the respondents were found to be appropriate food choice behavior. The food choice behavior of household respondents' were affected by Perception, social, culture, changes in household income, access to food, farm practice and productivity, food prices and food local systems and this is important for program planners and policy makers to improve the well -being of all vulnerable rural households in the study area. Therefore, local government and nongovernmental organizations should give emphasis for improving food choice behavior through continuous training, asset building and capital mobilization. Agro- ecology based intervention should also be taken to improve the food choice behavior of rural households in the study area. Agricultural extension and public health/sanitary extension services should be trained to deliver mutually reinforcing messages that promote sustainable food production, improved dietary intakes, and improved sanitation and health.
\end{abstract}

\section{Keywords}

Agro- ecology; Consumption score; Drivers of Change; Food choice; Malnutrition; Rural households; Perception 


\section{Introduction}

Food choice behavior of the individual is a complex process influenced by a variety of determinants related to the food, to the external environment and to the individual which interact to produce food choice [1]. Individual influences include physiological and psychological factors, acquired food preferences and knowledge and the interpersonal or social influences are, for example, the family and group influences [2].

Many people were affected by vitamin and mineral deficiencies - one out of three in developing countries. At the same time, 1.5 billion adults were overweight in 2008; this is due to inappropriate food consumption behavior including over 200 million obese men and nearly 300 million obese women [3]. In addition, a growing number of low and middleincome countries(LMC); are facing a double burden of malnutrition, i.e., the persistence of under-nutrition, notably among children, along with a rapid rise in overweight and obesity, and diet-related chronic diseases [4; 5].

The development of agricultural and food systems must be viewed in the context of sustainable development. It must take into account the progressive depletion of fossil energy, the protection of soil and water resources, the preservation of biodiversity and the issue of climate change. If they are to feed more than nine billion people by 2050, farmers around the world will have to produce crops using less fossil fuel in an environmentally friendly way. They will also have to provide energy and industrial commodities in place of Petrochemical products, as well as environmental and rural services like water management, biodiversity protection, carbon sequestration, or diversified and open landscapes. In addition, food consumption habits will need to adapt towards these global challenges the world is facing. The foresight study by [6] clearly shows that by 2050 eating patterns and food consumption habit will be a major issue for world food security due to increasing population globally.

Socio-cultural beliefs and customs have a significant influence on family nutritional well-being. In terms of food choice, some foods are more prized than others and a meal is never considered complete until they are included and enriched with additional food groups such as fats/ oils, fruits, vegetables etc. [7]. Unfortunately, cultural food beliefs and taboos are often related to foods of animal origin in the study area. Cultural influences may also include perception towards certain food choice and food preparation besides environment, socio-economic and demographic characteristics of the rural households. Moreover, the connection between the perception of rural households towards nutritionally dense foods, socio- economic and demographic characteristics and environmental factors and food choice behavior were poorly emphasized. In addition, the prevalence of under nutrition and the kinds of food available to address under nutrition but could not due issues associated with food choice behavior like social, culture, institution and environment besides socio- economic and demographic characteristics in the study area. This study is focused on assessing food choice behavior and consumption among rural household and the perception towards Nutritionally Dense Foods using eight different food items aggregated from FAO food balance sheet and the factors influencing their decision for consumption

\section{Research Methodology}

\subsection{Description of the Study Area}

Adola Rede district is located in southern part of Oromia, Ethiopia, at a distance of $468 \mathrm{~km}$ from Finfine. Astronomically the district is located between $5^{\circ} 44^{\prime} 10^{\prime \prime}-6^{\circ} 12^{\prime} 38^{\prime \prime}$ latitudes and $38^{\circ} 45^{\prime} 10^{\prime \prime}-39^{\circ} 12^{\prime} 37^{\prime \prime}$ longitudes. It shares boundary with Ana Sora in the North-West, Wadera in the South- East and Odo Shakiso in the south and Girja in the North- East directions. It has the total area of about $1254.56 \mathrm{~km}^{2}$. Most of the earth surface of the district has an undulating land surface with an elevation ranging from 1350 to 2340 meters. The district is characterized by three agro- climatic zones, namely humid, sub humid and dry arid zones. In terms of the agricultural calendar, the rain fall pattern of the district is bimodal for lowlands and midland areas and uni-modal for highland parts. The dry arid agro- climatic zones attributed to little rainfall while the humid agro- climatic zones receives extremely high rainfall. Like in many parts of Ethiopia, the farming system is still traditional with oxen and yolk (animal's power), and labour as the major means of production during land preparation, planting and harvesting as well as post harvest process. Rain-fed agriculture is a common practice for many farm households in this district. However, a semi-nomadic economic activity is also practiced as a means of livelihood by some of its residents. This district has 29 peasant associations and two urban centers. The farmers of this district produce both in autumn and spring seasons. They produce cereals such as teff, wheat, barley and maize, pulses such as haricot bean, and others such as fruits and vegetables. Overall, wheat, maize and teff are the major 
crops cultivated by the farmers in this study area. They also engaged in the production of coffee as means of livelihood. Furthermore, ownership large number of livestock by farmers indicates district potential for livestock production.

Culture plays a major role in the tourism industry. Particularly, hierarchical decadency of a society from the ancient time to the present development trend of the district, specially the Geda system of the Guji Caste which is a culturally accepted administrative process done hierarchically where by power is transformed from one to the other after 8 years.

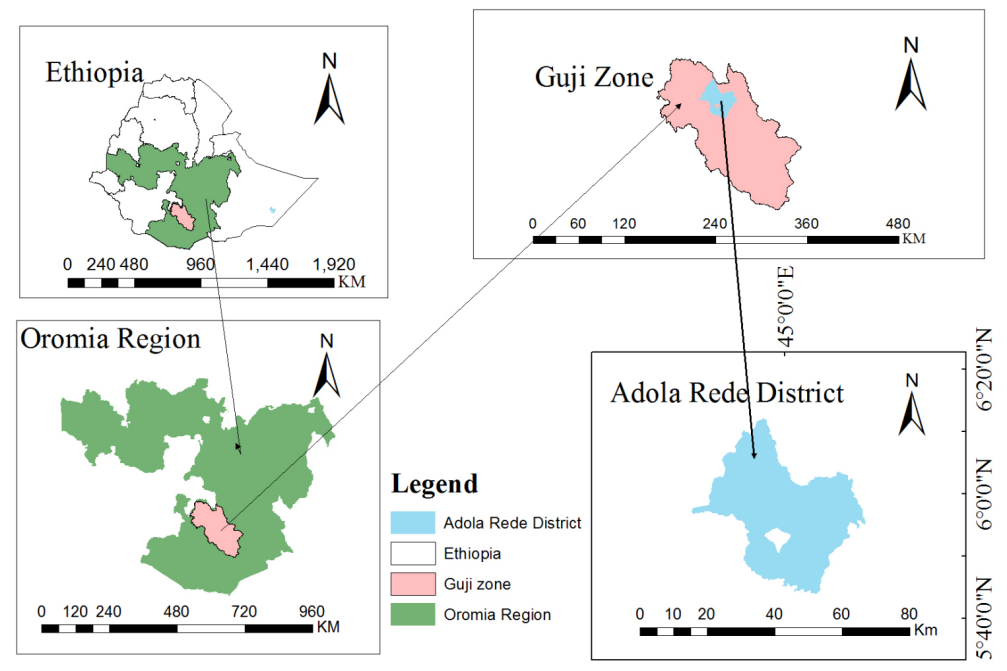

Figure 1. Map of the study area.

\subsection{Sample Size and Sampling Techniques}

In this study, samples of 150 rural households were taken from this district by using the rule of thumb that stated in the regression analysis there should be at least ten (10) respondents per each independent variable at $95 \%$ confidence interval [8]. In order to select these respondents and study sites, multi-stage sampling techniques were employed. First, 29 peasant associations in Adola Rede district were stratified in to three agro-ecological zones with 15 peasant associations low land, 11 peasant associations midland and 3 peasant associations highland. Numbers of study sites were also determined by using probability proportional to size (PPS) techniques. Second, simple random sampling (SRS) techniques were used to draw sample peasant associations from each stratum and probability proportional to size were used to determine sample households for the selected peasant associations. Third, simple random sampling (SRS) techniques were used to draw sample households for the respective study peasant associations using comprehensive sample frame of respective peasant associations.

Table 1. Peasant associations, number of households and sample size used for this study.

\begin{tabular}{llccc}
\hline No. & $\begin{array}{c}\text { Name of peasant } \\
\text { associations }\end{array}$ & Agro-ecological zones & Household size & Sample size \\
\hline 1 & Dande & Lowland & 651 & 22 \\
2 & Oda buta & Lowland & 750 & 26 \\
3 & Bacere & Lowland & 788 & 27 \\
4 & Gobicha & Midland & 630 & 22 \\
5 & Dole & Midland & 894 & 30 \\
6 & Maleka & Highland & 673 & 23 \\
Total sample & & & 4386 & 150 \\
\hline
\end{tabular}

\subsection{Types, Sources and Method of Data Collection}


The study was focused on rural households' food choice preferences for different eight food items aggregated from FAO food balance sheet and the factors influencing their decision for consumption. To undertake this study the primary data was used. The primary data was collected from the rural households of this district using semi- structured interview and key informant interview and focus group discussions. The survey questionnaire was prepared in English and translated to local language ("Afan Oromo") so as to get precise information from the households since this language is used by the residents in this district. The semi- structured interview schedule was pre-tested at randomly selected rural households of different peasant associations assumed to have matching characteristics of the study sites from each agroecology before conducting the survey. It was to make essential amendments on such things as ordering and wording of questions and coverage of the interview schedule.

\subsection{Data Analysis}

Statistical Package for Social Science (SPSS) version 20 was used for data entry and analysis. Descriptive statistics like mean, percentages, standard deviation and frequencies were used in analyzing socio economic characteristics of the respondents. Inferential statistical tools like chi- square and F- test were also used. The type of food groups consumed over the 7-days diet recall period was used from food frequency questioners containing all the sixteen food groups of FAO food balance sheet in order to capture household's food choice behavior rather than 24 hours recall period, thereby reducing the risk of selection bias [9; 10]. The food choice behavior of the rural households was categorized depending on Food Consumption Score (FCS) used widely by World Food Program [11] to indicate adequate or inadequate dietary diversity or food consumption behavior for the households constructed using FCS by multiplying the frequency of each food group by its weight which gives 'weighted food group values and summing values over the 8 groups (theoretical range $=0$ - 112). Different weights, ranging from 0.5 to 4 , were applied to the food groups according to their nutrient density $[11 ; 12]$ as indicated in TABLE 2 below. The FCS was divided into three level categories:

Level: 1 A FCS more than 35 as adequate food choice behavior, given value two (2).

Level: 2 A FCS from 21.5 to 35 as borderline food choice behavior, given value one (1); and

Level: 3 A FCS less than or equal to 21 was classified as poor food choice behavior, given value zero $(0)$

The FCS was calculated by using the following steps:

I). Using standard 7-days food frequency data, group all the food items from the comprehensive FAO food balance sheet into eight specific food groups; these are: 1) starches,2) pulses, 3) vegetables, 4) meat, 5) dairy, 6) fruits, 7) fats/oil and 8) sweets(TABLE 2);

II). Sum all the consumption frequencies of food items of the same group, and recode the value of each group above 7 as 7 ( 7 is an upper limit);

III). Multiply the values obtained for each food group by its weight and create new weighted food group scores;

IV). Sum the weighed food group scores, thus creating the food consumption score (FCS) and;

V). Using the appropriate thresholds and recode the variable food consumption score, from a continuous variable to a categorical variable.

Table 2. Eight different aggregated food groups, from sixteen food groups of FAO food balance sheet and different weights, ranging from 0.5 to 4 , according to their nutrient density.

\begin{tabular}{|c|l|l|c|}
\hline No & Food groups from FAO food balance sheet & Aggregated into eight food groups & Weight values \\
\cline { 1 - 2 } 1 & Cereals & \multirow{2}{*}{ 1). Starches } & 2 \\
\cline { 1 - 2 } 2 & Roots and tubers & \multirow{2}{*}{ 2). Vegetables } & \\
\cline { 1 - 2 } 3 & Vitamins A rich vegetables and tubers & & \\
\cline { 1 - 2 } & Dark green leafy vegetables & \\
\hline
\end{tabular}


Table 2. cont.

\begin{tabular}{|c|c|c|c|}
\hline No & Food groups from FAO food balance sheet & Aggregated into eight food groups & Weight values \\
\hline 6 & Vitamin A rich fruits & \multirow{2}{*}{ 3).Fruits } & \multirow{2}{*}{1} \\
\hline 7 & Other fruits & & \\
\hline 8 & Organ meat & \multirow{4}{*}{ 4). Meat } & \multirow{4}{*}{4} \\
\hline 9 & Flesh meats & & \\
\hline 10 & Eggs & & \\
\hline 11 & Fish and sea food & & \\
\hline 12 & Legumes, nuts and seeds & 5). Legumes & 3 \\
\hline 13 & Milk and milk products & 6). Dairy & 4 \\
\hline 14 & Oils and fats & 7). Fats & 0.5 \\
\hline 15 & Sweets & 8). Sweets & 0.5 \\
\hline 16 & Spices, condiments, beverage & - & 0 \\
\hline
\end{tabular}

Source: $[11 ; 12]$

\section{Results and Discussion}

\subsection{Food Choice Behavior and Consumption of the Respondents}

\subsubsection{Food consumption of the respondents}

Based on the study, of all the eight food groups such as starches, pulses, vegetables, fruits, meat, dairy, fats and sweets, starchy and vegetable food groups were consumed by every respondent of all agro ecologies. Starchy food groups were consumed frequently all the days during the diet recall period of this study and vegetable food groups also consumed even the consumption frequency varies when compared to starchy food groups while in contrast meat food groups were not consumed by any respondents during 7 days diet recall period and fruit food groups were only found consumed at mid-land agro- ecologies of the study area by $30.8 \%$ of the respondents who fell into adequate food choice behavior category. Pulse food groups mainly consumed in the lowland and mid-land agro-ecologies of the study area. The proportion of household respondents consuming pulse food groups from the lowland who fell into borderline and poor food choice behavior categories were $45.3 \%$ and $36 \%$ respectively while respondents from mid-land agro- ecologies who fell into borderline and adequate food choice behavior categories were $50 \%$ and $30.8 \%$ respectively (TABLE 3 ).

Only $30.4 \%$ of the respondents from the highland agro-ecology of the study area who fell into adequate food choice behavior category consumed pulse group foods. Regarding the dairy food groups' consumption of the respondents, household respondents from mid-land agro-ecologies who fell into borderline and adequate food choice behavior categories were 50\% and 30.8\% respectively while household respondents from lowland agro-ecologies who fell into borderline and adequate food choice behavior categories were $45.3 \%$ and $18.7 \%$ respectively and respondents from highland parts of the study area whose food consumption behavior fell into borderline and adequate were $34.8 \%$ and $30.4 \%$ consumed diary food groups during the diet recall period of this study. The proportion of household respondents from the lowland parts of the study area who fell into borderline and adequate food choice behavior categories consuming fat food groups were $45.3 \%$ and $18.7 \%$ respectively while respondents from mid-land agro- ecologies who fell into poor and adequate food choice behavior categories were $19.2 \%$ and $30.8 \%$ respectively and respondents from highland parts who fell into borderline and adequate food choice behavior were $34.8 \%$ and $30.4 \%$. With respect to sweet food groups, they were consumed only by respondents of lowland and mid-land but not in highland parts and by respondents of poor food choice behavior category. The proportion of lowland respondents who fell into borderline and 
adequate food choice behavior were $45.3 \%$ and $18.7 \%$ while those of mid-land agro-ecology who fell into borderline and adequate food choice behavior categories were $50 \%$ and $30.8 \%$ respectively.

Table 3. Proportion of food consumption behavior among household respondents of the three agro-ecologies.

\begin{tabular}{|c|c|c|c|c|c|c|c|c|c|}
\hline \multirow{3}{*}{$\begin{array}{l}\text { Food } \\
\text { groups }\end{array}$} & \multicolumn{3}{|c|}{ Poor FCB(n=45) } & \multicolumn{3}{|c|}{ Borderline $\mathrm{FCB}(\mathrm{n}=68)$} & \multicolumn{3}{|c|}{ Adequate $\operatorname{FCB}(n=37)$} \\
\hline & Lowland & Midland & Highland & Lowland & Midland & Highland & Lowland & Midland & Highland \\
\hline & $\%$ & $\%$ & $\%$ & $\%$ & $\%$ & $\%$ & $\%$ & $\%$ & $\%$ \\
\hline Starches & 100 & 100 & 100 & 100 & 100 & 100 & 100 & 100 & 100 \\
\hline Pulses & 36 & - & - & 45.3 & 50 & - & 30.8 & - & 30.4 \\
\hline Vegetables & 100 & 100 & 100 & 100 & 100 & 100 & 100 & 100 & 100 \\
\hline Diary & - & - & - & 45.3 & 50 & 34.8 & 18.7 & 30.8 & 30.4 \\
\hline Meat & - & - & - & - & - & - & - & - & - \\
\hline Fruits & - & - & - & - & - & - & - & 30.8 & - \\
\hline Fats & - & 19.2 & - & 45.3 & - & 34.8 & 18.7 & 30.8 & 30.4 \\
\hline Sweets & - & - & - & 45.3 & 50 & - & 18.7 & 30.8 & - \\
\hline
\end{tabular}

\subsubsection{Food choice behavior of the respondents}

The average FCS of the sample respondents was 34.27. The FCS of the sample respondents ranges from 19.5 to 54. Following World Food Program [11], out of 150 respondents interviewed, one-fourth of the total sampled rural households fell into appropriate food choice behavior category. $45 \%$ and $30 \%$ of the household respondents fell into borderline and poor food choice behaviors categories respectively. Rural households, who fell into borderline and poor food choice categories, were referred as food insecure.
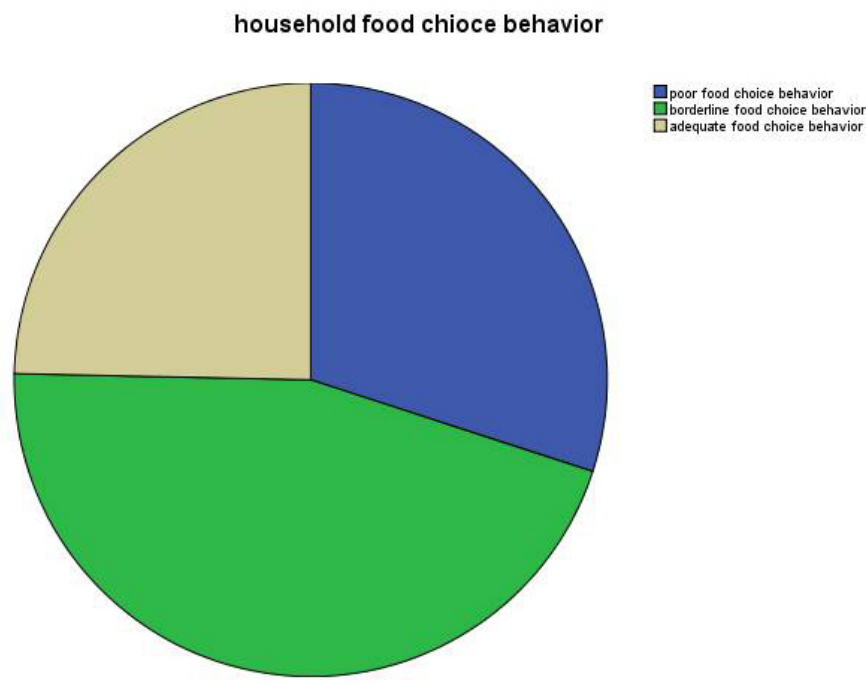

Figure 2. Proportion of household respondents' food choice behavior. 
Table 4. Food choice behavior of the respondents in the three agro ecologies.

\begin{tabular}{|c|c|c|c|c|c|c|}
\hline \multirow{2}{*}{$\begin{array}{l}\text { Agro- } \\
\text { ecologies }\end{array}$} & \multicolumn{2}{|c|}{ Poor $\operatorname{FCB}(n=45)$} & \multicolumn{2}{|c|}{ Borderline FCB $(n=68)$} & \multicolumn{2}{|c|}{ Adequate $\mathrm{FCB}(\mathrm{n}=37)$} \\
\hline & Food groups & Percent & Food groups & Percent & Food groups & Percent \\
\hline High land & $\begin{array}{l}\text { Starchy }^{7} \\
\text { Pulses }^{0} \\
\text { Vegetables }^{7} \\
\text { Fruits }^{0} \\
\text { Dairy }^{0} \\
\text { Meat }^{0} \\
\text { Fats }^{0} \\
\text { Sweets }\end{array}$ & 17.8 & $\begin{array}{l}\text { Starchy }^{7} \\
\text { Pulses }^{0} \\
\text { Vegetables }^{5} \\
\text { Fruits } \\
\text { Dairy }^{3} \\
\text { Meat }^{0} \\
\text { Fats }^{1} \\
\text { Sweets }\end{array}$ & 11.8 & $\begin{array}{l}\text { Starchy } \\
\text { Pulses }^{3} \\
\text { Vegetables }^{7} \\
\text { Fruits }^{0} \\
\text { Dairy }^{5} \\
\text { Meat }^{0} \\
\text { Fats }^{2} \\
\text { Sweets }\end{array}$ & 18.9 \\
\hline Mid- land & $\begin{array}{l}\text { Starchy }^{7} \\
\text { Pulses }^{0} \\
\text { Vegetables }^{5} \\
\text { Fruits }^{0} \\
\text { Dairy }^{0} \\
\text { Meat }^{0} \\
\text { Fats }^{1} \\
\text { Sweets }\end{array}$ & 22.2 & $\begin{array}{l}\text { Starchy } \\
\text { Pulse }^{2} \\
\text { Vegetables }^{5} \\
\text { Fruits } \\
\text { Dairy }^{2} \\
\text { Meat }^{0} \\
\text { Fats }^{0} \\
\text { Sweets }\end{array}$ & 38.2 & $\begin{array}{l}\text { Starchy }^{7} \\
\text { Pulses }^{5} \\
\text { Vegetables }^{4} \\
\text { Fruits } \\
\text { Dairy }^{3} \\
\text { Meat }^{0} \\
\text { Fats }^{1} \\
\text { Sweets }\end{array}$ & 43.2 \\
\hline Lowland & $\begin{array}{l}\text { Starchy }^{7} \\
\text { Pulses }^{1} \\
\text { Vegetables }^{3} \\
\text { Fruits }^{0} \\
\text { Dairy }^{0} \\
\text { Meat }^{0} \\
\text { Fats }^{0} \\
\text { Sweets }\end{array}$ & 60.0 & $\begin{array}{l}\text { Starchy } \\
\text { Pulse }^{2} \\
\text { Vegetables }^{3} \\
\text { Fruits } \\
\text { Dairy }^{2} \\
\text { Meat }^{0} \\
\text { Fats }^{1} \\
\text { Sweets }\end{array}$ & 50.0 & $\begin{array}{l}\text { Starch }^{7} \\
\text { Pulses }^{0} \\
\text { Vegetables }^{4} \\
\text { Fruits } \\
\text { Dairy }^{7} \\
\text { Meat }^{0} \\
\text { Fats } \\
\text { Sweets }^{2}\end{array}$ & 37.8 \\
\hline
\end{tabular}

Note: Numbers, 0, 1, 2, 3, 4, 5, 6 and 7 written at the right corner of the different food groups indicate consumption frequency of different food groups by the household respondents per 7 days diet recall period.

The result of key informants' interviews pointed out that the consumption behavior of the respondents in the three agroecologies were a bit different. For example rural households in the lowland agro- ecologies usually consume foods made from maize, local cabbage and dairy and its products and rarely pulses. Because of the harsh agro- ecologies, they annually receive little rain fall that hinders the production and productivity of the area. This is a challenge which is attributed to poverty. They even never store what they produce for reasonable price for food shortage period due to grain borer like weevil. Their crop production is not usually enough to sustain the livelihoods. The livelihood of the rural households living in the lowland agro ecologies depends mainly on livestock and livestock production. The respondents also reported that animal derived foods are socially and culturally accepted foods.

The food consumption of the rural households' in the mid-land agro-ecologies was found to be better than lowland and highland agro-ecologies. Because, the farming system of these mid-land agro ecologies of the study area is better than lowland and highland agro ecologies in terms of crop production. They produce starchy crops like Maize, Teff, Wheat, Barley, Sweet potato, and Irish potato. Pulses like haricot bean, Faba bean and rarely pea. Vegetables like local cabbage and head cabbage, lettuce and pepper. Fruits such as banana, avocado, mango, papaya lemon, orange and the like are prevailing in the mid-land parts of the study area. They usually integrate many of these food items in their meal but rarely fruits which ripens seasonally. Peoples residing in these areas have better chance of storing what they produce 
free from grain borer and have better chance of selling their products during reasonable price.

The highland parts of the study area also produce maize, barely, wheat, Irish potato from the starchy foods, faba bean, pea from the pulse groups, local and head cabbage and enset or locally called 'Wesi' from the vegetable groups. Animal rearing activity is also good when compared to mid-land agro ecology but extremely high rain fall and frost are another problems constraining on farm land and, decrease the production of the area. Beside these peoples in the highland of the study area usually consume enset with local cabbage and dairy and dairy products because enset and dairy along with its products are socially and culturally accepted foods. As it was recapitulated from focus group discussions and key informant interviews, the environment along with the economy which is influenced by demographic characteristics of the households drive the local capacity for varieties of food and hence availability and food choice behavior of the rural households in the study area.

\subsection{Perception of the Respondents towards Nutritionally Dense Foods like Animal Derived Foods, Vegetables and Fruits}

For the aim of this study it was important to assess the perception of rural households towards nutritionally dense foods. Perception level of sample respondents on indicators like quality of nutritionally dense foods to develop our body, protect us from disease, and make us strong and socially and culturally acceptable and their accessibility as compared to other food groups were collected qualitatively.

Perception of the rural households towards nutritionally dense foods like animal derived foods, vegetables and fruits is the insight and sensitivity of the rural households to consume these food groups with respect to social and cultural acceptability, ease of access and their importance for our body development, strength and health when compared to other food groups. Household respondents in the study area have no good thought towards nutritionally dense foods like Vegetables and Fruits regardless of their importance for our health and body development, as they cultivated under certain climatic and edaphic conditions. Vegetables and Fruits are capital and labor intensive to be cultivated by household respondents. These factors determine the productivity (output), which also determines prices to go high to offer, which in turn affects / influences food choice. Rural households of the study area were not intentionally integrating varieties of these fruits and vegetables in their daily meals. They are also perishable to produce once and as stock like other grains and consume regularly. Hence more concern for animal derived foods, as they are important for nourishing our body; provide strength, health and development and are socially and culturally acceptable.

As the result of focus group discussions summarized, food consumption behavior of the rural respondents of the study area is constrained by economic status of the households, and cultural and social acceptance of these food groups that can determine the consumption behavior of the rural households. Rural households in the study area have good insight and sensitivity towards animal derived foods (meat, milk, butter, cheese and yogurt) in all the three agro ecologies because these foods are culturally and socially accepted among all eight food groups. So the rural households perceive these animal derived foods as worth eating in their daily meals. But those economically poor status rural households constrained to consume in their daily diets. They sell dairy foods to the market and buy some of the other consumption commodities which are not available in their home and expenditure on health care, school fee, social affairs like 'ider', wedding, funeral ceremony and the like. It can also be visualized from TABLE 4 above that even though rural households' perception towards meat and dairy foods was good, none of the respondents consumed meat during the seven days recall period of this study. This is supported by key informants interview as well that concluded lack of economy coupled with environmental degradation caused by climatic change which drives the households not to produce more, influences access of nutritionally dense foods, especially animal derived foods and consequently, lack of adequate food choice behavior/food insecurity prevalence in the study area.

Food habits were among the oldest most entrenched aspects of cultures that exerted deep influence on the behavior and perception of respondents in the study area. The cultural background determined what were eaten as well as when and how. A respondents' culture had a lot of influence on the kinds of foods they eat in each community. In every part of the community of the three agro-ecologies in the study area, people had divers feeding habits that have been inherited from generation to generation in addition to environmental factors that limited the availability of varied food groups. Culture influenced the food choice and food preparation behavior of rural households in the study area as they were found to consume only socially and culturally familiar food groups in their locality and restricted institutionally by which the behavior of the societies in the communities is regulated. 


\subsection{Socio- economic and Demographic Characteristics of the Sample Households}

Table 5. Mean distribution of continuous variables of the three food choice behavior

\begin{tabular}{lllll}
\hline \multirow{2}{*}{ Characteristics } & $\begin{array}{l}\text { Poor FCB } \\
(\mathbf{n = 4 5 )}\end{array}$ & $\begin{array}{l}\text { Borderline } \\
\text { FCB(n=68) }\end{array}$ & $\begin{array}{l}\text { Adequate } \\
\text { FCB(n=37) }\end{array}$ & \multirow{2}{*}{ F value } \\
\cline { 2 - 5 } & Mean (St.dev.) & Mean (St.dev.) & \multicolumn{2}{l}{ Mean (St.dev.) } \\
\hline Age & $34.49(12.70)$ & $36.87(10.44)$ & $39.08(12.72)$ & 1.569 \\
Family size(AE) & $3.96(1.11)$ & $4.72(1.39)$ & $5.03(1.53)$ & $6.846^{* * *}$ \\
Dependency ratio & $.58(.16)$ & $.5518(.18)$ & $.5061(.18)$ & 1.860 \\
Livestock ownership(TLU) & $2.85(2.12$ & $6.42(3.49)$ & $10.93(5.73)$ & $44.333^{* * *}$ \\
Land holding(hector) & $1.67(1.31)$ & $2.8(1.65)$ & $5.03(1.55)$ & $15.921^{* * *}$ \\
Distance to the nearest market & $3.03(.82)$ & $2.78(.93)$ & $2.98(.83)$ & 1.362 \\
\hline
\end{tabular}

Note:*, ** and $* * *$ significant at $10 \%, 5 \%$ and $1 \%$ probability level and Standard deviation in parenthesis.

\section{Household size}

Total household size of each household was calculated in adult equivalent to examine the impact of the difference in household size to food choice behavior following [13]. The mean adult equivalent was 4.57. Households with adequate food choice behavior have relatively larger household size in adult equivalent(AE) (5.03) when compared with respondents that have medium food consumption behavior (4.72) and that of poor food consumption behavior (3.96) which indicates that household size with large numbers of children less than 14 years of age leads to poor household food choice behavior as they are not active enough to contribute in economically sound activities to improve livelihood in general and food choice behavior in particular. In contrast to this household size with large adult equivalent contribute to adequate food choice behavior by actively participate in any economic generating and farm activities. In addition to this, as summarized from Focus Group Discussions, large numbers of adult equivalent in the households indicates that there are large numbers of matured individuals that could differently interact to different societies with in their communities and there outside their communities and develop experience the way different food groups prepared and consumed and share to their household members persuading to change the consumption behavior of the households.

\section{Total land holding}

The average land holding size the rural households who had adequate food choice behavior were larger than those rural households with boarder line food choice behavior and the land holding size of those rural households with poor food choice behavior were relatively the smallest. The result from TABLE 4 indicates that $25 \%$ respondents who had adequate food choice behavior had relatively larger 5.03 hector to diversify crops both for home consumption and marketing. From the analysis result, the mean difference in land holding of the household respondents for the three food choice behavior categories show that there is the significant difference at $1 \%$ significant level.

\section{Livestock ownership (TLU)}

As indicated above different types of livestock are kept by sample respondents. Livestock is an integral part of the farming system in the study area and considered as indicators of wealth and prestige. The average livestock ownership in the study area is 6.7 in TLU. A marked difference was obtained among the three categories of consumption in terms of livestock ownership. This shows that households in the highest consumption category owned 3.8 times more livestock than households in the lowest category of consumption while households in the borderline consumption owned 2.3 times more livestock than households in the lowest consumption category. The mean difference in livestock holding of the household respondents for the three food choice behavior categories show that there is the significant difference at $1 \%$ significant level. 
Table 6. Frequency Distribution of Discrete Variables.

\begin{tabular}{|c|c|c|c|c|c|}
\hline \multirow[t]{2}{*}{ Characteristics } & & $\begin{array}{l}\text { Poor } \\
\text { FCB(n=45) }\end{array}$ & $\begin{array}{l}\text { Borderline } \\
\text { FCB }(n=68)\end{array}$ & $\begin{array}{l}\text { Adequate } \\
\text { FCB(n=37) }\end{array}$ & \multirow[t]{2}{*}{$\chi^{2}$ value } \\
\hline & & Percent & Percent & Percent & \\
\hline \multirow[t]{2}{*}{ Sex } & Male & 95.6 & 98.5 & 97.3 & 923 \\
\hline & Female & 4.4 & 1.5 & 2.7 & \\
\hline \multirow[t]{3}{*}{ Marital status } & Married & 95.6 & 97.1 & 97.3 & 2.113 \\
\hline & Single & 0 & 1.5 & 0 & \\
\hline & Widow & 4.4 & 1.5 & 2.7 & \\
\hline \multirow[t]{4}{*}{ Educational Status: } & Illiterate & 15.6 & 7.4 & 2.7 & $57.663 * * *$ \\
\hline & Grade1-Grade 4 & 77.8 & 61.8 & 37.8 & \\
\hline & Grade5-Grade8 & 6.7 & 29.4 & 18.9 & \\
\hline & $>$ Grade 8 & 0 & 1.5 & 40.5 & \\
\hline \multirow[t]{2}{*}{$\begin{array}{l}\text { Access to Extension } \\
\text { services }\end{array}$} & Yes & 88.9 & 94.1 & 94.6 & 1.358 \\
\hline & No & 11.1 & 5.9 & 5.4 & \\
\hline \multirow[t]{2}{*}{$\begin{array}{l}\text { Access to Credit } \\
\text { service }\end{array}$} & Yes & 8.9 & 16.2 & 27 & $4.831^{*}$ \\
\hline & No & 91.1 & 83.8 & 73 & \\
\hline \multirow[t]{3}{*}{ Agro- ecology } & Highland & 17.8 & 11.8 & 18.9 & $6.090^{*}$ \\
\hline & Mid-land & 22.2 & 38.2 & 43.2 & \\
\hline & Low land & 60.0 & 50.0 & 37.8 & \\
\hline \multirow[t]{3}{*}{ Soil fertility } & Good & 24.4 & 25 & 32.4 & 1.959 \\
\hline & Fair & 62.2 & 63.2 & 62.2 & \\
\hline & Poor & 13.3 & 11.8 & 5.4 & \\
\hline \multirow[t]{2}{*}{ Off/non-farm } & Yes & 4.4 & 2.9 & 2.7 & .251 \\
\hline & No & 95.6 & 97.1 & 97.3 & \\
\hline
\end{tabular}

Note: $* * *$ and $* * *=$ significant at $10 \%, 5 \%$ and $1 \%$ probability level respectively.

\section{Educational level}

As it is observed in TABLE 6 , from $25 \%$ household respondents of adequate food choice behavior, $40.5 \%$ household heads were grade 9 and above, $18.9 \%$ grade $5-8,37.8 \%$ were grade $1-4$. The percentage difference in education level of household respondents for the three food choice behavior categories shows that there is a significant difference at $1 \%$ significant level. The presence of literates in the household may be important for obtaining information from outside. For instance literate household heads can read and explain information concerning nutritionally dense foods and meal preparation and consumption to the illiterate household members and properly allocate different commodities for home consumption. The information delivered by head of the household to the household members is more important than other sources of information, because of the trust existing between them and the head of the family is in charge to manage any economic activities in the study area.

\section{Use of credit}

Credit is widely considered as one of the favorable factors for adequate food choice behavior. Because it can solve financial problems of rural households; purchase agricultural inputs, boost the production and productivity and therefore adjust food consumption behavior. 
During the last cropping season (2009/10 E.C.), $16.7 \%$ of the respondents received credit services only from the informal sources (local level money lenders) for different purposes while $83.3 \%$ did not get from any sources (TABLE 6). The reasons mentioned by respondents were Bank requires high collateral, loans from informal Sources were not available, and repayment terms are unfavorable for micro credit and saving services. But the conclusions from key informant interviews indicates that the majority of rural households in the study area persuade themselves not to receive loans especially from Oromia saving and credit institutions as they were not well trained about what and how to do with the loans they received. Because at the end of the day, they sell their assets to repay the loans that indicates loss rather than profit. On top of this, the perceptions of the rural households were not good towards this institution, despite, the availability of formal credit may help rural households in their efforts to cope with food availability and hence consumption behavior. The percentage difference in credit service of household respondents for the three food choice behavior categories shows that there is a significant difference at $10 \%$ significant level.

\section{Agro- ecology}

Agro- ecologies are geographical areas exhibiting similar climatic conditions that determine their ability to support rained agriculture. The result from TABLE 6 shows that only $18.9 \%$ and $37.8 \%$ of sample households in the highland and lowland respectively were adequate food choice behavior and $43.2 \%$ sampled households from the mid- land agroecology were also adequate food choice behavior. This is because households living in the highland parts of the study area usually eat enset with local cabbage and animal products while households living in the lowland agro- ecology of the study area suffered from little rain falls they received during the cropping season which hindered them to boost the production and productivity and crop diversification but they were found to be better of highland agro-ecology. Because they consumed animal derived foods more, and the weight value of these food groups is high, as they were characterized by semi nomadic ways of life. TABLE 6 revealed that the majority of the respondents (50\%) live in low land agroecology. While $34.7 \%$ were from the mid land and only $15.3 \%$ were from high land parts of the study area. The percentage difference in agro- ecology of household respondents for the three food choice behavior categories indicates as agro- ecology has significant influence on the food choice behavior of the respondents at $10 \%$ significance level.

\section{Conclusions and Recommendations}

The food choice behavior of rural households in the study area is a complex process influenced by a variety of complex and dynamic nature of determinants related to the food. This study did not capture this complex and dynamic nature of factors that affect food choice behavior of rural households, focused on understanding the connection between socioeconomic, demographic, environmental, institutional, cultural and social context and food choice behaviors of rural households in the study area. More over the 7- days recall period of Food Consumption Score is at risk of micronutrient deficiencies and likely having sever access food issues. This reference period does not: capture seasonal changes, quantify the food gap, capture intra- household consumption and show how food consumption has changed as a result of crisis, unless previous FCSs for same households (HHs) are available.

The results of this study revealed that only one fourth of the respondents proportion of household respondents' food choice behavior categories were adequate food choice behavior while borderline and poor food choice behavior categories were $45 \%$ and $30 \%$ respectively. This means that three-fourth of the household respondents were food/ nutrition insecure. The normal food choice behavior of household respondents' were affected by Perception, social, culture, changes in household income, access to food, farm practice and productivity, food prices and food local systems and this is important for program planners and policy makers to improve the well -being of all vulnerable rural households in the study area.

Therefore local government and non government organization should train rural households of the study area so as to change the perception of rural households towards nutritionally dense foods. Agro- ecology based intervention should also be taken to improve the food choice behavior of rural households in the study area. Agricultural extension and public health/sanitary extension services should be trained to deliver mutually reinforcing messages that promote sustainable food production, improved dietary intakes, and improved sanitation and health.

It should be important for policymakers to ensure that adequate food consumption or food security objectives are incorporated into national poverty reduction strategies which consider impacts at the household level. It should also be essential promoting environmentally and socially sustainable agricultural development as a foundation for economic growth. Looking beyond farming to include off farm income opportunities and the root causes of food insecurity by 
promoting not only productivity growth, but also resource access, land tenure and education should also be given due emphases

\section{Acknowledgment}

The author would like to gratitude Oromia Agricultural Research Institute (OARI), for financial support. The staff of Bureau of Agriculture and Natural Resource (BoANR) of Adola Rede district where the study conducted, and 150 household respondents along with key informants and focus groups for their interest in devoting their valuable time during the interview to make this research work flourishing.

\section{References}

[1] Murcott A.1998. The Nation's Diet - The social Science of food choice. London: Longman.

[2] Eertmans A, Baeyens F, Van den Bergh O.2001. Food likes and their relative importance in human eating behavior: review and preliminary suggestions for health promotion. Health Educ Res, 16(4):443-56.

[3] WHO 2011. Obesity and Overweight. Fact sheet No. 311, Updated March 2011, Geneva.

[4] FAO 2006. The State of Food Insecurity in the World: Addressing Food Insecurity in Protracted Crises. Rome.

[5] International Food and Research Institute 2014. Global Nutrition Report: Actions and Accountability to Accelerate the World's Progress on Nutrition. Washington, DC.

[6] Paillard, S., Treyer, S. \& Dorin, B. 2010. Agrimonde, Scenarios and Challenges for Feeding the World in 2050. QUAE, Versailles, France.

[7] RK Oniang'o, JM Mutuku and SJ Malaba 2003.Contemporary African food habits and their nutritional and health implications, 12 (3): 231-236

[8] http//www.statisticssolutions.com/sa, assessed date July10, 2017

[9] Carleto et al., 2013. Towards better measurement of household food security Harmonizing indicators and the role of household survey

[10] Horjus, P., Kennedy, G., Berardo, A., Papavero, C., Ballard, T., Dop, M.Brouwer, I. A. 2010. Proxy measures of household food consumption for food security assessment and surveillance: comparison of household dietary diversity and food consumption scores. Public Health Nutrition, 13 (12), 2010-2018.

[11] WFP 2008. Food Consumption Analysis: Calculation and use of the food consumption score in food security analysis.

[12] Vaitla, b., Tesfaye, G.mRounseville and Maxwell, D. 2012. Resilience and Livelihoods change in Tigray Ethiopia. Feinstein International Center, Tufts University.

[13] Storck, H., Bezabih Emana, Berhanu Adnew, A. Borowiccki and Shimelis W/Hawariat, 1991. Farming systems and resource economics in the tropics: farming system and farm management practices of smallholders in the Hararghe highland. Vol.11, Wissenschaftsverlag Vauk, Kiel, Germany.

\section{Appendices}

Table 7. Numerical value, level, statistical limits and value description of food choice behavior categories

\begin{tabular}{llll}
\hline Level & Numerical value & Statistical limits & Value description \\
\hline 1 & 2 & $>35$ & Adequate food choice behavior \\
2 & 1 & $21.5-35$ & Border line food choice behavior \\
3 & 0 & $\leq 21$ & Poor food choice behavior \\
\hline
\end{tabular}

Source: [11] 